\title{
DEVELOPMENT OF ACTIVATED HYDROCHAR FROM PADDY STRAW FOR NUTRIENT ADSORPTION AND CROP WATER MANAGEMENT
}

\author{
GAJASINGHE ARACHCHIGE GANGA KAVINDI \& ZHONGFANG LEI \\ Graduate School of Life and Environmental Sciences, University of Tsukuba, Japan
}

\begin{abstract}
Hydrochar, a low-cost carbonaceous material, has wide environmental applications including hazardous chemicals immobilization/removal and moisture conservation. It is a by-product of the hydrothermal carbonization process under subcritical water condition. There are several distinct characteristics prevailing with hydrochar like microporosity, ion exchange capacity, water holding capacity, large specific surface area, and low H:C and O:C ratios. The type of feedstock material mainly determines the chemical composition of hydrochar. Paddy straw is an available crop residue in Asian countries including Sri Lanka with great potential for utilization as the feedstock for producing hydrochar. Due to its great cation exchange capacity (CEC), hydrochar is expected to adsorb $\mathrm{P}$ and $\mathrm{N}$ efficiently. Additionally, it is applicable as an effective crop moisture conservation technique. In this research, hydrochar was produced by using hydrothermal carbonization (HTC) method under different HTC temperatures and treatment durations, following by the determinations of $\mathrm{P}$ and $\mathrm{N}$ adsorption capacity and water holding capacity to evaluate the feasibility of using hydrochar as a moisture conservation technique. Hydrochar production was carried out using paddy straw at $100^{\circ} \mathrm{C}, 200^{\circ} \mathrm{C}$ and $250^{\circ} \mathrm{C}$ for 0,60 and 120 min, respectively. The char yield, $\mathrm{pH}$, electrical conductivity (EC), maximum moisture absorption capacity, and $\mathrm{P}$ and $\mathrm{N}$ adsorption capacity were determined. Maximum moisture absorption with $5.39 \mathrm{~g} / \mathrm{g}$ and the minimum moisture loss $26 \%$ was observed in $\mathrm{T}_{5}$ hydrochar $\left(200^{\circ} \mathrm{C}\right.$, $60 \mathrm{~min}$ ). Therefore $\mathrm{T}_{5}$ is the most suitable hydrochar type as a moisture conservation technique at tropical condition. $\mathrm{T}_{8}$ hydrochar $\left(250^{\circ} \mathrm{C}, 60 \mathrm{~min}\right)$ has the maximum $\mathrm{N}$ adsorption $(11.73 \mathrm{mg} / \mathrm{g})$ at an initial $50 \mathrm{mg} / \mathrm{L} \mathrm{NH}_{4}-\mathrm{N}$ concentration. The optimal temperature for hydrochar production for better NH4-N sorption capacity is around $250^{\circ} \mathrm{C}$. However, all the tested hydrochar samples showed limited $\mathrm{PO}_{4}-\mathrm{P}$ adsorption. Hence hydrochar modifications required for better $\mathrm{PO}_{4}-\mathrm{P}$ adsorption.
\end{abstract}

Keywords: hydrochar, paddy straw, hydrothermal carbonization, moisture absorption, $P$ and $N$ adsorption.

\section{INTRODUCTION}

As a low-cost carbonaceous material, biochar has wide environmental applications, including removal of hazardous chemicals and moisture conservation. As an alternative for activated carbon, biochar is a by-product of thermochemical conversion such as pyrolysis, gasification, torrefaction and hydrothermal carbonization of organic solid waste. Biochar has several distinct characteristics, such as microporosity, ion exchange capacity, water holding capacity, large specific surface area, and low $\mathrm{H}: \mathrm{C}$ and $\mathrm{O}: \mathrm{C}$ ratios [1] These characteristics play a pivotal role in the applicability and the efficiency of biochar.

It is well known that physical and chemical properties of biochar depend on several factors. The type of feedstock material mainly determines the chemical components of biochar. In addition, microporosity and surface area of biochar increase at higher temperatures. Another important factor is the production technique. Pyrolysis is used to produce biochar, bio-oil and syngas at the same time, while hydrothermal carbonization (HTC) can produce comparatively less syngas content with higher yields of hydrochar and bio-oil [2]. Hydrochar is regarded as a promising technique applicable for wet feedstock, at 
it has several advantages over biochar, including mild reaction temperature, low activation energy and exothermic biomass hydrolysis which facilitate less energy consumption.

Paddy straw is a freely available crop residue in Sri Lanka with great potential of being utilized as feedstock for hydrochar production. Ahmad et al. [2] claimed that hydrochar produced from rice straw, wheat straw, coir dust or groundnut shell had comparatively higher yield due to the availability of $\mathrm{K}$ and $\mathrm{Zn}$. Therefore, using straw materials is cost-effective with nutrients-rich hydrochar achieved. In addition, it can reduce the crop waste generation as well as reduce $\mathrm{CO}_{2}$ emission due to carbon sequestration.

Leachate of phosphorus $(\mathrm{P})$ and nitrogen $(\mathrm{N})$ from agriculture lands is a burden because they are regarded as the main contributors to eutrophication. Further, the growing concern about the $\mathrm{P}$ availability in future urges to find tangible $\mathrm{P}$ recovery mechanisms. Since hydrochar has greater cation exchange capacity (CEC), and those rich in metal ions exhibit better $\mathrm{P}$ adsorption capacity [3], it is possible to use hydrochar to adsorb of $\mathrm{P}$ and $\mathrm{N}$.

As a consequence of climate change, irregular rainfall with prolonged drought period is one of the major threats to crop production in Sri Lanka. Thus, application of moisture conservation technique is a must for farmlands to avoid the yield losses caused by moisture stress. Bikbulatova et al. [4] reported that the water retention capacity of biochar as a moisture conservation measure with the improvement of the soil conditions. However, there is lack of information regarding the water holding capacity of hydrochar.

In this research it is expected to determine the water holding capacity of hydrochar at tropical temperature and evaluate the influence of processing temperature and holding time over the moisture absorption capacity of hydrochar in addition to its $\mathrm{N}$ and $\mathrm{P}$ adsorption capacity.

\section{MATERIALS AND METHODOLOGY}

\subsection{Production of hydrochar}

In this study hydrochar was prepared by using paddy straw collected from a local farm in Ibaraki, Japan. Paddy straw was air dried and crushed by using a crusher (Wonder crush/mill, WDL-1, Japan) and sieved by a mesh of $500 \mu \mathrm{m}$. Then the paddy straw powder was fed in to hydrothermal reactor (OM Labtech, MMJ-200, Japan) with a working volume of $200 \mathrm{ml}$, $20 \mathrm{MPa}$ maximum pressure and $300^{\circ} \mathrm{C}$ maximum temperature. The exposing temperature and holding time for the hydrothermal carbonization of biomass are listed in Table 1.

Table 1: Experimental conditions for hydrothermal carbonization (HTC) of paddy straw.

\begin{tabular}{lccc}
\hline \multirow{2}{*}{ HTC temperature $\left({ }^{\circ} \mathrm{C}\right)$} & \multicolumn{3}{c}{ HTC holding time (min) } \\
\cline { 2 - 4 } & 0 & 60 & 120 \\
\hline 100 & $\mathrm{~T}_{1}$ & $\mathrm{~T}_{2}$ & $\mathrm{~T}_{3}$ \\
200 & $\mathrm{~T}_{4}$ & $\mathrm{~T}_{5}$ & $\mathrm{~T}_{6}$ \\
250 & $\mathrm{~T}_{7}$ & $\mathrm{~T}_{8}$ & $\mathrm{~T}_{9}$ \\
\hline
\end{tabular}

Note: Biomass/water ratio 1:10 (w/v), no other chemicals addition, and $\mathrm{pH}$ adjustment.

HTC experiments were carried out in an air tight condition and the reactor was kept for $1 \mathrm{~h}$ to be cooled to room temperature $\left(27^{\circ} \mathrm{C}\right)$. Then the reactor was opened and the resultant char was taken out to dry at $105^{\circ} \mathrm{C}$ for $24 \mathrm{~h}$ at a Sanyo MOV-112F (U) convection oven. Dried sample was crushed and sieved by a mesh of $500 \mu \mathrm{m}$ and stored in air tight packs. The hydrochar yield was calculated according to following eqn (1). 


$$
\text { Yield }=\mathrm{M}_{\mathrm{H}} / \mathrm{M}_{\mathrm{RS}} * 100,
$$

where $\mathrm{M}_{\mathrm{H}}$ is the weight of hydrochar (g) and $\mathrm{M}_{\mathrm{RS}}$ is the weight of paddy straw (g).

\subsection{Hydrochar characterization}

For the $\mathrm{pH}$ measurement, firstly a mixture of hydrochar: distilled water ratio 1:20 (w/v) was kept in a shaker at $100 \mathrm{rpm}$ for $2 \mathrm{~h}$. Then the $\mathrm{pH}$ of the suspension was measured with a $\mathrm{pH}$ meter (Laqua twin pH meter, Japan) and recorded. EC measurement was done in the same suspension with an electrical conductivity meter (Cemco multifunctional portable tester, EC5, China). Bulk density of char sample was measured firstly by putting the oven dried $\left(105^{\circ} \mathrm{C}\right)$ and sieved (by a mesh of $\left.500 \mu \mathrm{m}\right)$ hydrochar into a $10 \mathrm{ml}$ test tube and getting the weight. Then the bulk density in $\mathrm{kg} / \mathrm{m}^{3}$ was calculated according to the eqn (2).

$$
\text { Bulk density }=\mathrm{M} / \mathrm{V} * 1000 \text {, }
$$

where $\mathrm{V}$ is volume of hydrochar $(10 \mathrm{ml})$ sample, and $\mathrm{M}(\mathrm{g})$ is weight of $10 \mathrm{ml}$ of hydrochar.

Volatile matter content and ash content of hydrochar were determined by burning char samples in a muffle furnace (Fine, F-1404-P, Japan) at $600^{\circ} \mathrm{C}$ for $4 \mathrm{~h} . \mathrm{C}, \mathrm{H}, \mathrm{N}$ and O elemental composition was analysed using a CHN elemental analyzer (Perkin-Elmer 2400 II, USA). The $\mathrm{O}$ content was calculated by the balance as per the eqn (3).

$$
\mathrm{O} \%=100 \%-(\mathrm{C} \%+\mathrm{H} \%+\mathrm{N} \%+\mathrm{ash} \%) .
$$

Hydrogen to carbon $(\mathrm{H} / \mathrm{C})$ and oxygen to carbon $(\mathrm{O} / \mathrm{C})$ atomic ratios were calculated by the eqns (4) and (5), respectively.

$$
\begin{gathered}
\mathrm{H} / \mathrm{C}=\left(\mathrm{H} \% / \mathrm{M}_{\mathrm{H}}\right) /\left(\mathrm{C} \% / \mathrm{M}_{\mathrm{C}}\right), \\
\mathrm{O} / \mathrm{C}=\left(\mathrm{O} \% / \mathrm{M}_{\mathrm{O}}\right) /\left(\mathrm{C} \% / \mathrm{M}_{\mathrm{C}}\right),
\end{gathered}
$$

where $\mathrm{H} \%, \mathrm{C} \%, \mathrm{~N} \%$ and $\mathrm{O} \%$ are the weight percentage of $\mathrm{H}, \mathrm{C}, \mathrm{N}$ and $\mathrm{O}$ in the hydrochar, and $\mathrm{M}_{\mathrm{H}}, \mathrm{M}_{\mathrm{C}}$, and $\mathrm{M}_{\mathrm{O}}$ are atomic weight of $\mathrm{H}, \mathrm{C}$ and $\mathrm{O}$, respectively.

\subsection{Moisture absorption experiment}

Moisture absorption capacity of produced hydrochar was determined by placing $1 \mathrm{~g}$ of each hydrochar sample in a $50 \mathrm{ml}$ centrifuge tube containing $40 \mathrm{ml}$ distilled water. All the tubes were kept in a water bath shaker at $100 \mathrm{rpm}$ and $30^{\circ} \mathrm{C}$ for $24 \mathrm{~h}$. After $24 \mathrm{~h}$ shaking, hydrochar was collected by filtration and those samples were kept in air tight containers to drain all the excess water. Then the wet sample was carefully transferred to a pre-weighted container and the weight of moist hydrochar was obtained. Dry weight of hydrochar was collected after drying at $105^{\circ} \mathrm{C}$ for $24 \mathrm{~h}$ until no further moisture loss was detected. Moisture absorption capacity in $\mathrm{g} / \mathrm{g}$ of hydrochar was calculated as per the eqn (6)

$$
\text { Moisture absorption }=\left(\mathrm{M}_{2}-\mathrm{M}_{3}\right) /\left(\mathrm{M}_{3}-\mathrm{M}_{1}\right) \text {, }
$$

where $M_{1}$ is the weight of the oven dried container (g), $M_{2}$ is the weight of wet hydrochar and container (g), and $\mathrm{M}_{3}$ is the weight of oven dried hydrochar and container (g). Moisture absorption was calculated as grams of moisture absorbed for per one gram of hydrochar. 


\subsection{Moisture absorption rate and kinetics}

Moisture absorption rates of all the hydrochar samples and raw rice straw powder were determined as batches at 4, 8, 12, 16, 20 and 24 h respectively. The calculation was done by using the eqn (6).

Lagergren's pseudo-first kinetic model [5] for moisture absorption was calculated and plotted based on the data collected at moisture absorption rate, as shown in eqn (7)

$$
\log (\mathrm{Qe}-\mathrm{Qt})=\log \mathrm{Qe}-\left(\mathrm{K}_{1} \mathrm{t} / 2.303\right),
$$

where Qe is absorption at equilibrium (g/g), Qt is absorption at $\mathrm{t}$ time (g/g), $\mathrm{t}$ is time (h) and $\mathrm{K}_{1}$ is first rate constant $\left(\mathrm{h}^{-1}\right)$.

\subsection{Water holding capacity at $40^{\circ} \mathrm{C}$}

Moisture loss percentage of moist hydrochar samples was examined at $40^{\circ} \mathrm{C}$ in a muffle furnace for the determination of its water holding capacity at higher temperature. Weight loss of sample was recorded in one hour intervals till a constant weight being arrived. Eqn (8) was used to calculate the moisture loss

$$
\text { Moisture loss }(\%)=\left(\mathrm{M}_{\mathrm{i}}-\mathrm{M}_{\mathrm{t}} / \mathrm{M}_{\mathrm{i}}\right) * 100,
$$

where $\mathrm{M}_{\mathrm{t}}$ is moisture content at t time and $\mathrm{M}_{\mathrm{i}}$ is initial moisture content.

Water holding capacity at $40^{\circ} \mathrm{C}$ was determined based on the moisture loss percentage

\subsection{PO4-P adsorption capacity}

$100 \mathrm{mg} / \mathrm{L}$ phosphate stock solution was firstly prepared with potassium phosphate monobasic $\left(\mathrm{KH}_{2} \mathrm{PO}_{4}\right)$ in analytical grade. $\mathrm{P}$ adsorption capacity was determined using batch adsorption experiments. $0.1 \mathrm{~g}$ of hydrochar sample was placed in each $50 \mathrm{ml}$ centrifuge tube containing $30 \mathrm{ml}$ of $5 \mathrm{mg} / \mathrm{L} \mathrm{P}$ solution which was prepared from the stock solution. The tightly sealed containers were placed in a water bath shaker at $100 \mathrm{rpm}$ and $27^{\circ} \mathrm{C}$ for $24 \mathrm{~h} .5 \mathrm{ml}$ aliquots of each sample were collected and filtered through $0.22 \mu \mathrm{m}$ filters. P concentration was determined by UV spectrophotometer using the standard phosphorus molybdenum blue method. The analysis was carried out twice with average value being reported. $\mathrm{P}$ adsorption capacity was calculated according to eqn (9)

$$
\mathrm{q}_{\mathrm{e}}=\left(\mathrm{C}_{0}-\mathrm{C}_{\mathrm{e}}\right) \mathrm{V} / \mathrm{m} \text {, }
$$

where $C_{o}$ is the initial concentration $(\mathrm{mg} / \mathrm{L}), \mathrm{C}_{e}$ is the concentration at the equilibrium $(\mathrm{mg} / \mathrm{L})$, $\mathrm{V}$ is the volume of the solution (L), and $\mathrm{m}$ is the weight of char (g).

\subsection{NH4-N adsorption experiments}

A stock solution of $200 \mathrm{mg} / \mathrm{L} \mathrm{N}$ was prepared from analytical grade ammonium chloride $\left(\mathrm{NH}_{4} \mathrm{Cl}\right)$. $\mathrm{N}$ adsorption capacity was also determined using batch adsorption experiments. $0.1 \mathrm{~g}$ of hydrochar sample was mixed with $30 \mathrm{ml}$ of $50 \mathrm{mg} / \mathrm{L} \mathrm{NH}_{4}-\mathrm{N}$ solution in a $50 \mathrm{ml}$ centrifuge tube. The entire batch adsorption test was carried out at $100 \mathrm{rpm}$ and $27^{\circ} \mathrm{C}$ for $24 \mathrm{~h} .5 \mathrm{ml}$ aliquots of each sample were collected and filtered through $0.22 \mu \mathrm{m}$ filter. Indophenols standard method was used to determine the $\mathrm{NH}_{4}-\mathrm{N}$ concentration on UV spectrophotometer [6]. $\mathrm{NH}_{4}-\mathrm{N}$ adsorption capacity was also calculated according to eqn (9). 


\section{RESULT AND DISCUSSION}

\subsection{Effect of processing conditions on the physiochemical properties of hydrochar}

Pressure of the hydrothermal reactor was increased automatically along with the increasing temperature and holding time. Breakeven point of increasing the pressure (1.2 MPa) was observed at $200^{\circ} \mathrm{C}$ for holding time of $0 \mathrm{~min}$, with the maximum pressure (4 MPa) generated at $250^{\circ} \mathrm{C}$. Reactor pressure tended to increase with the presence of subcritical water pressure along with the gases phase pressure and facilitated carbonisation process at low temperature [7]. Although reduction in hydrochar yield was observed, the ash content was increased with the increasing temperature and holding time. Liu et al. [8] also reported that the yield reduction and increasing of the ash content with respective to the increasing hydrothermal temperature. As illustrated in Table 2, the lowest yield percentage (44.95\%) and the maximum ash percentage (30\%) were observed in the $\mathrm{T}_{9}\left(250^{\circ} \mathrm{C}, 120 \mathrm{~min}\right)$. Degradation of the lignocelluloses compounds with the cleavage of glycosidic bonds increased with the increase in the process temperature.

Table 2: Yield, bulk density, solid percentage, $\mathrm{pH}$ and EC of paddy straw mediated hydrochar.

\begin{tabular}{cccccccccc}
\hline & $\mathrm{T}\left({ }^{\circ} \mathrm{C}\right)$ & $\begin{array}{c}\text { Time } \\
(\mathrm{min})\end{array}$ & $\mathrm{P}(\mathrm{MPa})$ & $\begin{array}{c}\text { Yield } \\
(\%)\end{array}$ & $\begin{array}{c}\mathrm{BD} \\
\left(\mathrm{kg} / \mathrm{m}^{3}\right)\end{array}$ & $\begin{array}{c}\mathrm{OM} \\
(\%)\end{array}$ & $\begin{array}{c}\text { Ash } \\
(\%)\end{array}$ & $\mathrm{pH}$ & $\begin{array}{c}\mathrm{EC} \\
(\mathrm{ms} / \mathrm{cm})\end{array}$ \\
\hline $\mathrm{T}_{0}$ & \multicolumn{1}{c}{ paddy straw } & - & - & 189 & 88.00 & 12.00 & 7.7 & 2.76 \\
$\mathrm{~T}_{1}$ & 100 & 0 & 1.0 & 81.50 & 146 & 88.00 & 12.00 & 6.5 & 2.48 \\
$\mathrm{~T}_{2}$ & 100 & 60 & 1.0 & 81.50 & 152 & 86.00 & 14.00 & 6.3 & 2.69 \\
$\mathrm{~T}_{3}$ & 100 & 120 & 1.0 & 81.40 & 149 & 88.24 & 11.76 & 5.6 & 2.86 \\
$\mathrm{~T}_{4}$ & 200 & 0 & 1.2 & 78.25 & 153 & 84.00 & 16.00 & 5.1 & 3.30 \\
$\mathrm{~T}_{5}$ & 200 & 60 & 1.5 & 60.10 & 168 & 82.00 & 18.00 & 4.8 & 4.50 \\
$\mathrm{~T}_{6}$ & 200 & 120 & 1.5 & 58.20 & 142 & 78.00 & 22.00 & 5.7 & 2.11 \\
$\mathrm{~T}_{7}$ & 250 & 0 & 4.0 & 56.50 & 295 & 78.00 & 22.00 & 5.4 & 3.02 \\
$\mathrm{~T}_{8}$ & 250 & 60 & 4.0 & 50.55 & 390 & 72.00 & 28.00 & 5.8 & 3.82 \\
$\mathrm{~T}_{9}$ & 250 & 120 & 4.0 & 44.95 & 330 & 70.00 & 30.00 & 5.1 & 3.63 \\
\hline $\mathrm{T}=$ temperature; P = generated pressure at hydrothermal reactor; BD = bulk density; OM = organic matter content.
\end{tabular}

The bulk density of the char was reduced compared to the feedstock at higher process temperature, reflecting the improvement of porosity of the char. The lowest bulk density, $142 \mathrm{~kg} / \mathrm{m}^{3}$ was observed in the $\mathrm{T}_{6}$ hydrochar sample. The $\mathrm{pH}$ value decreased while the EC value increased with the increase of the process temperature, and the lowest $\mathrm{pH}$ and the maximum EC were observed in the $\mathrm{T}_{5}$ sample $\left(200^{\circ} \mathrm{C}, 60 \mathrm{~min}\right)$. Wang et al. [9] also reported that the reduction of $\mathrm{pH}$ occurred with the formation of organic acid which is an intermediate substance during the HTC reaction process.

As per the results in Table 3, carbon percentage of $\mathrm{T}_{9}$ hydrochar was increased by $6.88 \%$ but the $\mathrm{O}$ and $\mathrm{H}$ percentages decreased by $0.75 \%$ and $24.66 \%$, respectively, when compared to the raw rice straw. There is some relationship between the processing condition 
(temperature and holding time) and the changes of $\mathrm{C}, \mathrm{H}$ and $\mathrm{O}$ atomic percentage of the produced char. At the same time the reduction of $\mathrm{O}$ and $\mathrm{H}$ content provides evidence of the breakage of $\mathrm{H}-\mathrm{O}$ bonds in the biomass and volatilization throughout the hydrothermal reaction process. Some previous works reported about the cleavage of $\mathrm{C}=\mathrm{C}, \mathrm{C}-\mathrm{C}$ and $\mathrm{H}-\mathrm{O}$ bonds through the thermal treatment of biomass and the generation of aromatic rings [4], [9], [10]. The lowest $\mathrm{H} / \mathrm{C}$ atomic ratio (1.19) was observed in $\mathrm{T}_{9}$, while the feedstock has the maximum $\mathrm{H} / \mathrm{C}$ atomic ratio. Char with a lower $\mathrm{H} / \mathrm{C}$ atomic ratio is considered as indicator for increasing char aromaticity which facilitates the stability over chemical or microbial degradation [11]. Similarly, the O/C atomic ratio was decreased with the increasing temperature and holding time. According to Table $3, \mathrm{~T}_{8}$ and $\mathrm{T}_{9}$ reflected the lowest $\mathrm{O} / \mathrm{C}$ ratios, 0.35 and 0.32 , respectively. The sharp decline of $\mathrm{O} / \mathrm{C}$ ratio at $250^{\circ} \mathrm{C}$, signals the comparatively higher oxidation of the biomass at that temperature. Fig. 1 shows the Van Krevelen diagram for hydrochar produced in the experiments, providing the information of the dehydration and depolymerisation gradient with respective to the processing temperature and holding time. According to Fig. $1, \mathrm{~T}_{8}$ and $\mathrm{T}_{9}$ demonstrated the significant depolymerisation compared to other hydrochar samples.

Table 3: Elemental composition and ratios of different hydrochar samples.

\begin{tabular}{lccccccc}
\hline Hydrochar type & $\mathrm{C} \%$ & $\mathrm{H} \%$ & $\mathrm{~N} \%$ & $\mathrm{O} \%$ & $\mathrm{H} / \mathrm{C}$ & $\mathrm{O} / \mathrm{C}$ & $(\mathrm{N}+\mathrm{O}) / \mathrm{C}$ \\
\hline $\mathrm{T}_{0}-$ paddy straw & 38.52 & 5.30 & 0.29 & 43.89 & 1.64 & 0.86 & 0.86 \\
$\mathrm{~T}_{1}-100^{\circ} \mathrm{C}, 0$ min & 39.11 & 5.21 & 0.55 & 43.13 & 1.59 & 0.83 & 0.84 \\
$\mathrm{~T}_{2}-100^{\circ} \mathrm{C}, 60$ min & 39.28 & 5.32 & 0.39 & 41.01 & 1.61 & 0.78 & 0.79 \\
$\mathrm{~T}_{3}-100^{\circ} \mathrm{C}, 120$ min & 39.83 & 5.30 & 0.37 & 42.74 & 1.59 & 0.81 & 0.81 \\
$\mathrm{~T}_{4}-200^{\circ} \mathrm{C}, 0$ min & 39.71 & 5.02 & 0.57 & 38.70 & 1.51 & 0.73 & 0.74 \\
$\mathrm{~T}_{5}-200^{\circ} \mathrm{C}, 60$ min & 40.45 & 4.88 & 0.86 & 35.81 & 1.44 & 0.66 & 0.68 \\
$\mathrm{~T}_{6}-200^{\circ} \mathrm{C}, 120$ min & 39.47 & 5.13 & 0.47 & 32.93 & 1.55 & 0.63 & 0.64 \\
$\mathrm{~T}_{7}-250^{\circ} \mathrm{C}, 0$ min & 40.05 & 4.77 & 0.51 & 32.67 & 1.42 & 0.61 & 0.62 \\
$\mathrm{~T}_{8}-250^{\circ} \mathrm{C}, 60$ min & 45.32 & 4.47 & 0.79 & 21.42 & 1.18 & 0.35 & 0.37 \\
$\mathrm{~T}_{9}-250^{\circ} \mathrm{C}, 120$ min & 45.40 & 4.55 & 0.82 & 19.23 & 1.19 & 0.32 & 0.33 \\
\hline
\end{tabular}
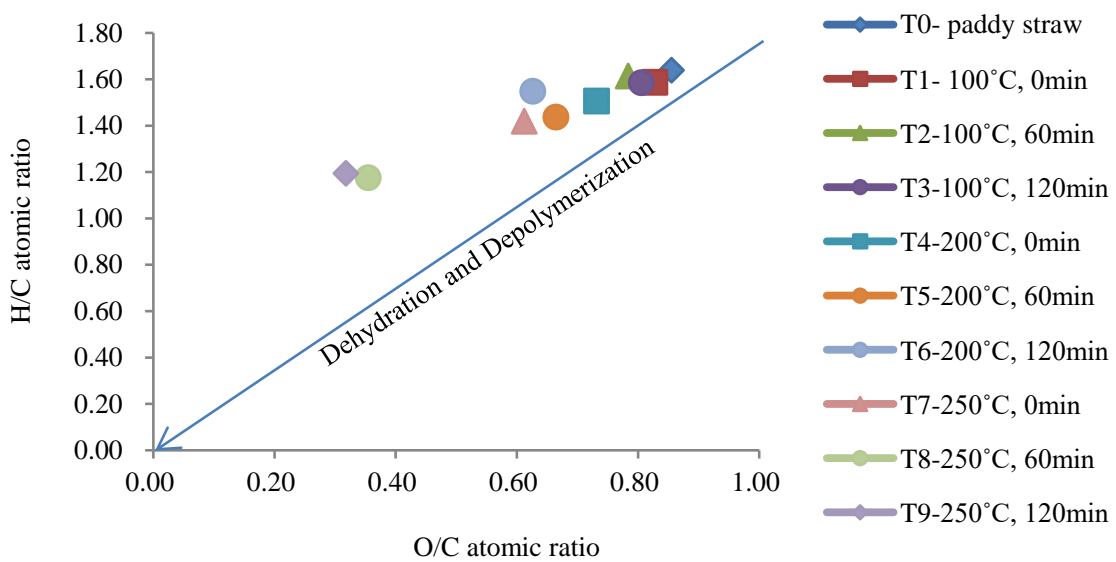

Figure 1: Van Krevelen diagram for the produced hydrochar. 


\subsection{Water holding capacity of hydrochar}

According to Fig. 2, the raw paddy straw has the lowest water absorption capacity of $2.41 \mathrm{~g} / \mathrm{g}$. The moisture absorption capacity of the produced hydrochar significantly increased with the increase in processing temperature. More specifically, the absorption rate significantly increased when the temperature higher than $200^{\circ} \mathrm{C}$ for holding longer than 0 min, indicating the relationship of holding time in the hydrochar production process for the development of char with higher water holding capacity. However, the maximum water absorption among the tested hydrochar was 5.39 and $5.17 \mathrm{~g}$ /g-hydrochar for $\mathrm{T}_{5}$ and $\mathrm{T}_{9}$, respectively. Equilibrium absorption was achieved after $12 \mathrm{~h}$ in most of the char samples. It has been reported that water absorption and water holding capacity of biochar depend on pore volume, pore structure functional groups and surface area [4]. While the surface area of hydrochar produced at lower temperatures has comparatively lower surface area than biochar. As Kambo and Dutta [12] pointed out, although biochar has well organized graphite layers, hydrochar has spear shaped aggregates and comparatively lower surface area. It is possible to consider that the improved porosity with increasing temperature played the pivotal role in moisture absorption in hydrochar.

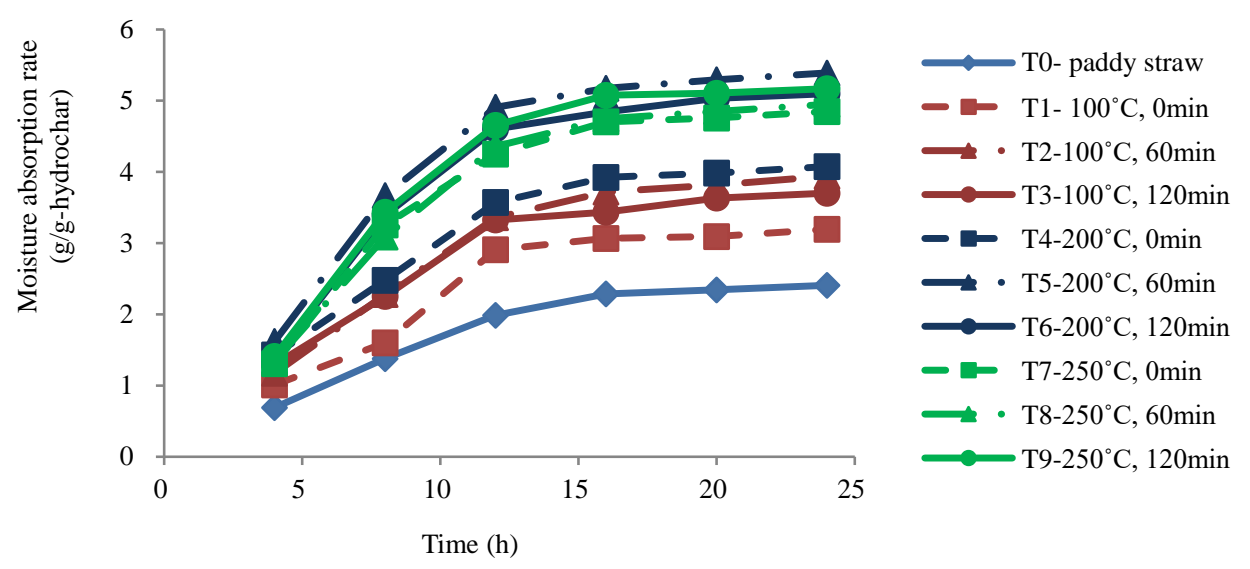

Figure 2: Moisture absorption rate of different hydrochar samples over time.

The experimental scatter diagram of $\log \left(\mathrm{q}_{\mathrm{e}}-\mathrm{q}_{\mathrm{t}}\right)$ verses time is illustrated in Fig. 3. The linear equation which resembles the eqn (7), theoretical moisture absorption rate, experimental moisture absorption rate, $\mathrm{R}^{2}$ value, and gradient value in addition to the firstrate constant $\left(\mathrm{K}_{1}\right)$ are listed in Table 4 . Since $\mathrm{R}^{2}$ values of all the samples are greater than 0.900 , it seems that the moisture absorption rate of hydrochar well fitted the linear equation. Hence, the moisture absorption rate of hydrochar was compatible with Lagergren's pseudofirst kinetic model. The kinetic process of absorption is well described by the reaction models. Further Lagergren's pseudo-first kinetic model is believed to be the first model used for kinetic modelling. In addition, the pseudo first-order kinetic model is usually applicable for determination of physical adsorptions capacities [13]. Therefore, the moisture absorption of hydrochar most probably depends upon the physical absorption rather attracted by the surface functional groups. 

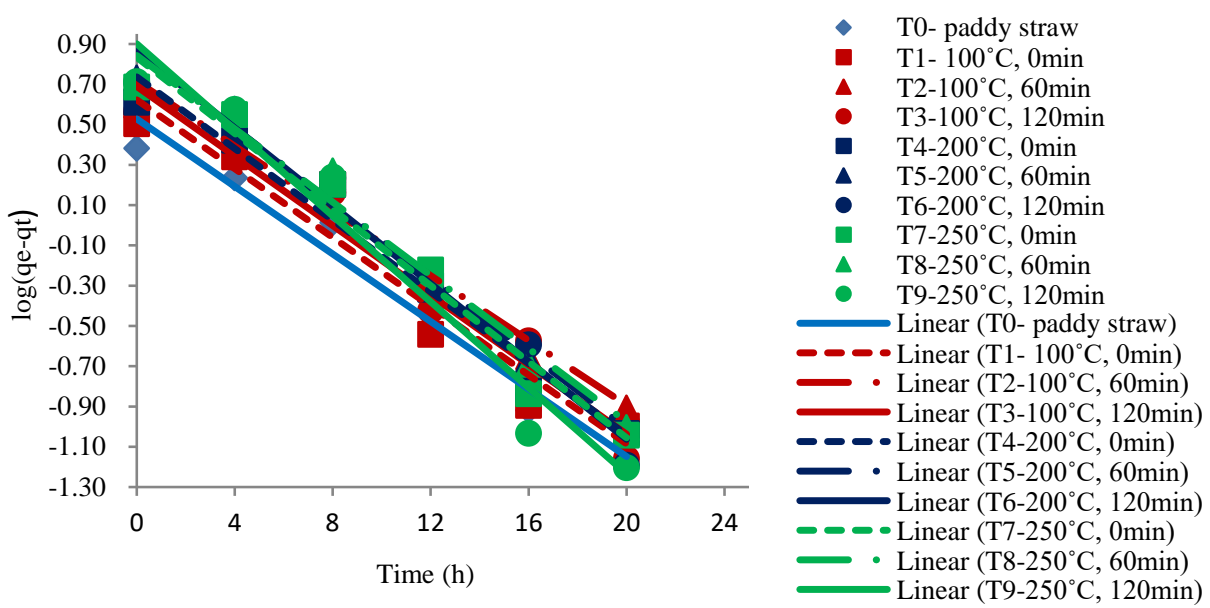

Figure 3: First-order model of moisture absorption and kinetics for different hydrochar.

Table 4: First-order model equations and kinetics during moisture absorption.

\begin{tabular}{ccccccc}
\hline Treatment & Equation & $\mathrm{R}^{2}$ & $\mathrm{Q}_{\mathrm{e}}$ & $\mathrm{q}_{\mathrm{e}}$ & $\mathrm{m}$ & $\mathrm{K}_{1}$ \\
\hline $\mathrm{T}_{0}$ & $\mathrm{y}=-0.0838 \mathrm{x}+0.528$ & 0.965 & 3.37 & 2.41 & 0.0838 & 0.019 \\
$\mathrm{~T}_{1}$ & $\mathrm{y}=-0.0854 \mathrm{x}+0.6227$ & 0.937 & 4.19 & 3.19 & 0.0854 & 0.020 \\
$\mathrm{~T}_{2}$ & $\mathrm{y}=-0.0804 \mathrm{x}+0.7145$ & 0.975 & 5.18 & 3.94 & 0.0804 & 0.019 \\
$\mathrm{~T}_{3}$ & $\mathrm{y}=-0.0863 \mathrm{x}+0.6893$ & 0.964 & 4.89 & 3.70 & 0.0863 & 0.020 \\
$\mathrm{~T}_{4}$ & $\mathrm{y}=-0.0889 \mathrm{x}+0.7366$ & 0.970 & 5.45 & 4.08 & 0.0889 & 0.020 \\
$\mathrm{~T}_{5}$ & $\mathrm{y}=-0.0931 \mathrm{x}+0.8544$ & 0.982 & 7.15 & 5.39 & 0.0931 & 0.021 \\
$\mathrm{~T}_{6}$ & $\mathrm{y}=-0.0966 \mathrm{x}+0.8689$ & 0.972 & 7.39 & 5.10 & 0.0966 & 0.022 \\
$\mathrm{~T}_{7}$ & $\mathrm{y}=-0.0945 \mathrm{x}+0.8338$ & 0.970 & 6.82 & 4.85 & 0.0945 & 0.022 \\
$\mathrm{~T}_{8}$ & $\mathrm{y}=-0.091 \mathrm{x}+0.8427$ & 0.975 & 6.96 & 4.95 & 0.091 & 0.021 \\
$\mathrm{~T}_{9}$ & $\mathrm{y}=-0.1067 \mathrm{x}+0.9007$ & 0.957 & 7.96 & 5.17 & 0.1067 & 0.025 \\
\hline
\end{tabular}

$\mathrm{Q}_{\mathrm{e}}=$ theoretical moisture absorption rate according to equation; $\mathrm{K}_{1}=$ first rate constant; $\mathrm{q}_{\mathrm{e}}=$ experimental moisture absorption rate; $\mathrm{m}=$ slope or gradient.

As seen in Fig. 4, the maximum moisture loss (38\%) was observed in $\mathrm{T}_{9}$ after $4 \mathrm{~h}$, and the minimum moisture loss (26\%) was detected in $\mathrm{T}_{5}$. The comparative water holding capacity with increasing temperature is illustrated in Fig. 5. As seen, $3.99 \mathrm{~g} / \mathrm{g}$ moisture absorption rate was estimated for $T_{5}$, while $3.20 \mathrm{~g} / \mathrm{g}$ moisture absorption rate for $T_{9}$. Although both $T_{5}$ and $\mathrm{T}_{9}$ have relatively greater moisture absorption rate at $30^{\circ} \mathrm{C}, \mathrm{T}_{9}$ has the minimum water holding capacity at $40^{\circ} \mathrm{C}$. According to Liu et al. [8], the mean pore size of hydrochar increased with the increase in processing temperature. On the other hand, the water holding capacity of char is increased with the increase of micropore volume. The macropores might be responsible for transportation of water in to micropores rather moisture retention [4]. In addition, the rearrangement of particles and formation of secondary pores with particle aggregation possibly depend on the wetting and drying process of hydrochar [14]. This might be the possible reason for the resultant lower water holding capacity at $T_{9}$. 


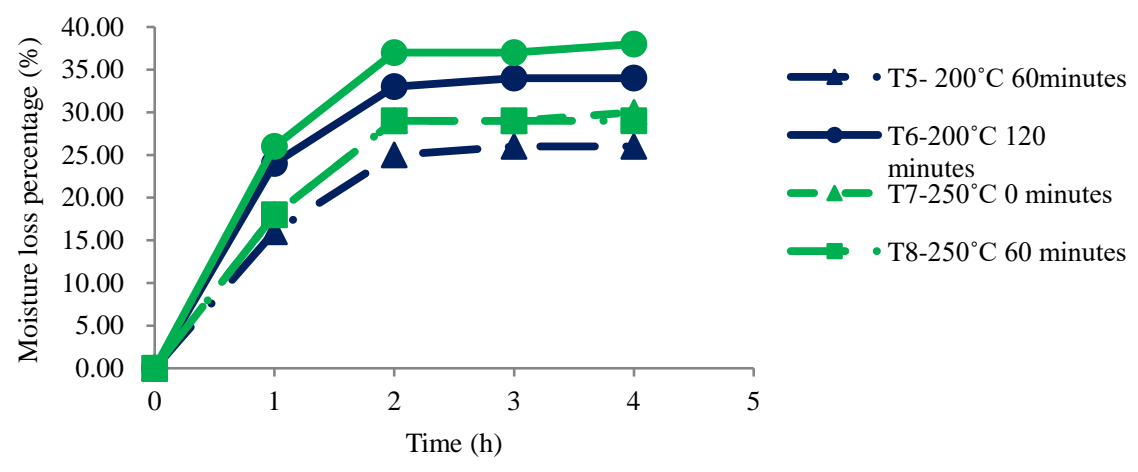

Figure 4: Moisture loss percentage of different hydrochar samples at $40^{\circ} \mathrm{C}$.

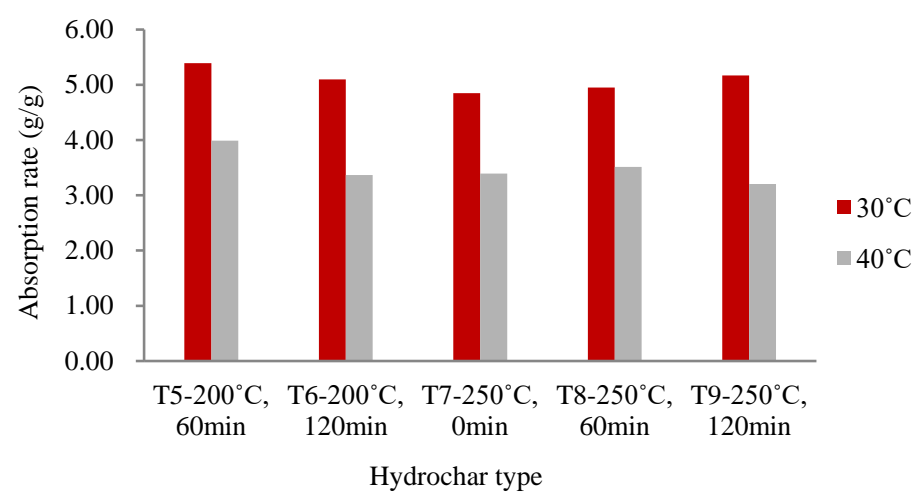

Figure 5: Comparative water holding capacity of different hydrochar at $30^{\circ} \mathrm{C}$ and $40^{\circ} \mathrm{C}$.

\subsection{Nutrients adsorption}

Fig. 6 illustrates the $\mathrm{NH}_{4}-\mathrm{N}$ adsorption capacity of hydrochar samples, among which $\mathrm{T} 8$ has the maximum $\mathrm{N}$ adsorption (11.73mg/g) at an initial $50 \mathrm{mg} / \mathrm{L} \mathrm{NH}_{4}-\mathrm{N}$ concentration. Although $\mathrm{NH}_{4}-\mathrm{N}$ adsorption is comparatively low for the raw straw feedstock, hydrochar samples showed substantial increased adsorption rate. For instance, $\mathrm{T}_{5}$ with an adsorption capacity of $10.55 \mathrm{mg} / \mathrm{g}$ has the lowest adsorption capacity among all the tested char samples. This phenomenon might be resulted from the increasing hydroxide ions and the acidity during the HTC process, in which the reaction rate of hydrochar tend to increase [9]. Since the $\mathrm{pH}$ of the tested char is comparatively low, the reaction rate seems to be increased compared to the raw feedstock. In contrary, $\mathrm{PO}_{4}-\mathrm{P}$ adsorption is comparatively lower in the tested hydrochar samples, showing the limitation of applicability of the obtained hydrochar for $\mathrm{P}$ recovery. According to Fig. 7 , $T_{9}$ reached the maximum $P$ adsorption $(0.32 \mathrm{mg} / \mathrm{g})$ at an initial $5 \mathrm{mg} / \mathrm{L} \mathrm{PO}_{4}-\mathrm{P}$ concentration. Fang et al. [15] reported that hydrochar has limited affinity for anions due to its negative surface charges. Therefore, $\mathrm{P}$ adsorption capacity can be improved through modification of char with metal ions such as K, Zn and Mg or acids [16]. 


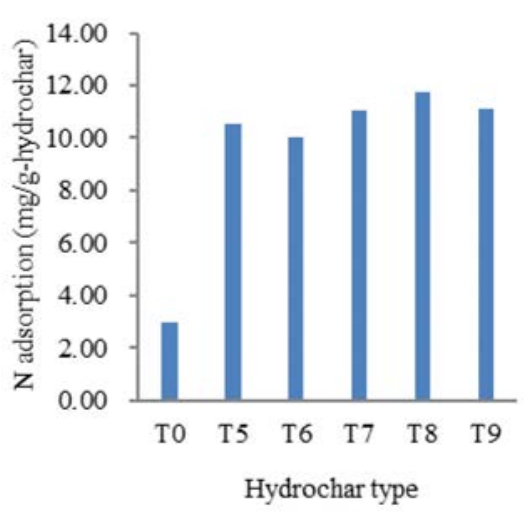

Figure 6: $\mathrm{NH}_{4}-\mathrm{N}$ adsorption capacity of hydrochar.

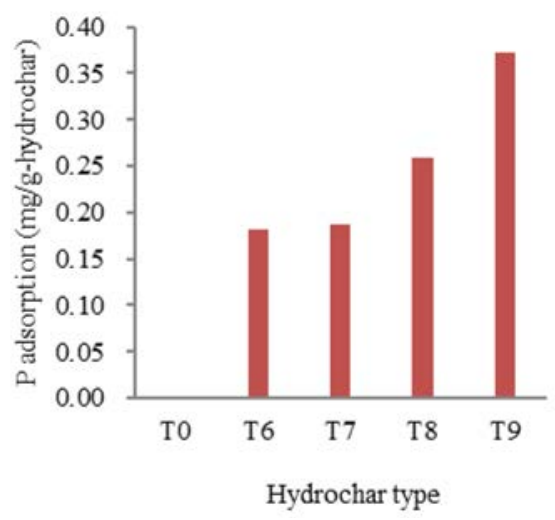

Figure 7: $\quad \mathrm{PO}_{4}-\mathrm{P}$ adsorption capacity of hydrochar.

\section{CONCLUSION}

Moisture absorption capacity of hydrochar is possibly improved by increasing the processing temperature and holding time. Among all the tested conditions, the maximum moisture absorption with $5.39 \mathrm{~g} / \mathrm{g}$ and the minimum moisture loss $26 \%$ was observed in $\mathrm{T}_{5}\left(200^{\circ} \mathrm{C}\right.$, $60 \mathrm{~min}$ ), meaning that $\mathrm{T}_{5}$ is the most suitable hydrochar type as a moisture conservation technique at tropical condition. Moisture absorption rate of hydrochar was found to well fit the Lagergren's pseudo-first kinetic model. Thus, the moisture absorption of hydrochar mainly depends on the physical absorption. Both $\mathrm{T}_{8}$ and $\mathrm{T}_{9}$ have comparatively higher $\mathrm{NH}_{4}{ }^{-}$ $\mathrm{N}$ adsorption capacity, indicating that the optimal temperature for hydrochar production for better $\mathrm{NH}_{4}-\mathrm{N}$ sorption capacity is around $250^{\circ} \mathrm{C}$. However, all the tested hydrochar samples showed limited $\mathrm{PO}_{4}-\mathrm{P}$ adsorption, which might be improved by modification with metal ions.

\section{ACKNOWLEDGEMENT}

G.A.G. Kavindi would like to express her gratitude to the JDS program for the financial support for her graduate study at University of Tsukuba, Japan.

\section{REFERENCES}

[1] Oliveira, F.R., Patel, A.K., Jaisi, D.P., Adhikari, S., Lu, H. \& Khanal, S.K., Environmental application of biochar: Current status and perspectives. Bioresource Technology, 246, pp. 110-122, 2017. http://dx.doi.org/10.1016/j.biortech.2017.08.122.

[2] Ahmad, M. et al., Biochar as a sorbent for contaminant management in soil and water: A review. Chemosphere, 99, pp. 19-23, 2014. http://dx.doi.org/10.1016/j.chemosphere.2013.10.071.

[3] Takaya, C.A., Fletcher, L.A., Singh, S., Anyikude, K.U. \& Ross, A.B., Phosphate and ammonium sorption capacity of biochar and hydrochar from different wastes. Chemosphere, 145, pp. 518-527, 2016. http://dx.doi.org/10.1016/j.chemosphere.2015.11.052.

[4] Bikbulatova, S., Tahmasebi, A., Zhang, Z., Rish, S.K. \& Yu, J., Understanding water retention behavior and mechanism in bio-char. Fuel Processing Technology, 169, pp. 101-111, 2018. http://dx.doi.org/10.1016/j.fuproc.2017.09.025. 
[5] Ho, Y.S., Citation review of Lagergren kinetic rate equation on adsorption reactions. Scientometrics, 59(1), pp. 171-177, 2004.

[6] Ivan, I. \& Degobbis, D., An optimal manual procedure for ammonia analysis in natural waters by the indophenol blue method. Water Research, 18(9), pp. 1143-1147. https://doi.org/10.1016/0043-1354(84)90230-6.

[7] Wiedner, K., Naisse, C., Rumpel, C., Pozzi, A., Wieczorek P. \& Glaser B., Chemical modification of biomass residues during hydrothermal carbonization: What makes the difference, temperature or feedstock? Organic Geochemistry, 54, pp. 91-100. http://dx.doi.org/10.1016/j. orggeochem.2012.10.006.

[8] Liu, Y., Yao, S., Wang, Y., Lu, H., Kaur, S. \& Yang, S., Bio- and hydrochars from rice straw and pig manure: Inter-comparison. Bioresource Technology, 235, pp. 332337, 2017. http://dx.doi.org/10.1016/j.biortech.2017.03.103.

[9] Wang, T., Zhai, Y., Zhu, Y., Li, C. \& Zeng, G., A review of the hydrothermal carbonization of biomass waste for hydrochar formation: Process conditions, fundamentals, and physicochemical properties. Renewable and Sustainable Energy Reviews, 90(Mar.), pp. 223-247, 2018. https://doi.org/10.1016/j.rser.2018.03.071.

[10] Li, X. et al., Functional groups determine biochar properties ( $\mathrm{pH}$ and EC) as studied by two-dimensional ${ }^{13} \mathrm{C}$ NMR correlation spectroscopy. PLOS One, 8(6), pp. 1-7, 2013. https://doi.org/10.1371/JOURNAL.PONE.0065949.

[11] Crombie, K., Masek, O., Sohi, S.P., Brownsort, P. \& Cross, A., The effect of pyrolysis conditions on biochar stability as determined by three methods. GCB Bioenergy, 5, pp. 122-123, 2013. https://doi.org/ 10.1111/gcbb.12030.

[12] Kambo, H.S. \& Dutta, A., A comparative review of biochar and hydrochar in terms of production, physico-chemical properties and applications. Renewable and Sustainable Energy Reviews, 45, pp. 359-378, 2015. http://dx.doi.org/10.1016/j.rser.2015.01.050.

[13] Qiu, H., Lv, L., Pan, B., Zhang, Q., Zhang, W. \& Zhang, Q., Critical review in adsorption kinetic models. Journal of Zhejiang University SCIENCE A, 10(5), pp. 716-724, 2009. https://doi.org/10.1631/jzus.A0820524.

[14] Mendoza, K.V. \& Horn, R., Effect of biochar addition on hydraulic functions of two textural soils. Geoderma, 326(Feb.), pp. 88-95, 2018.

https://doi.org/10.1016/j.geoderma.2018.03.021.

[15] Fang, J., Zhan, L., Ok, Y.S. \& Gao, B., Minireview of potential applications of hydrochar derived from hydrothermal carbonization of biomass. Journal of Industrial and Engineering Chemistry, 57, pp. 15-21, 2018. https://doi.org/10.1016/j.jiec.2017.08.026.

[16] Park, J.H. et al., Evaluation of phosphorus adsorption capacity of sesame straw biochar on aqueous solution: Influence of activation methods and pyrolysis temperatures. Environmental Geochemistry and Health, 37, pp. 969-983, 2015. https://doi.org/10.1007/s10653-015-9709-9. 